\title{
Perancangan dan Simulasi Trainer Human Machine Interface (HMI) untuk Media Pembelajaran Berbasis CX Designer PLC
}

\author{
Fitroh Anugrah Kusuma Yudha ${ }^{1,}$, , Bambang Riyanta, b \\ Program Studi Teknik Mesin, Fakultas Teknik, Universitas Muhammadiyah Yogyakarta \\ Jl. Brawijaya, Kasihan, Bantul, Yogyakarta 55183 \\ ayudha2.91@gmail.com, briyantab@yahoo.com
}

\begin{abstract}
Abstrak
Penelitian ini bertujuan untuk membuat rancangan media pembelajaran pada mata kuliah Programmable Logic Controller (PLC) berupa trainer Human Machine Interface ( $\mathrm{HMI}$ ) berbasis $\mathrm{CX}$ Designer yang terintergrasi dengan $\mathrm{CX}$ Programmer. Desain HMI yang tepat akan membuat pengujian program lebih mudah dan efisien. Sebagai media pembelajaran HMI memberikan efektifitas informasi yang dibutuhkan, sehingga perencanaan dapat dilakukan dengan efisiensi yang maksimal. Metode penelitian yang digunakan adalah metode eksperimental dan pembuatan rancangan produk berupa trainer untuk penguji program oleh mahasiswa atau operator. Dapat disimpulkan hasil dari penelitian ini bahwa penggunaan simulasi HMI berbasis CX Disigner dapat digunakan untuk memahami logika rangkaian suatu program dengan sangat mudah dan cepat untuk melatih ketrampilan pemograman PLC.
\end{abstract}

Kata kunci: PLC, HMI, CX Disigner, CX-Programmer

\begin{abstract}
This research aims to design a learning media for programmable logic controller (PLC) course in the form of Human Machine Interface (HMI) trainers based on $C X$ Designer integrated with $C X$-Programmer. The suitable HMI design result in easier and more efficient for program evaluating. As a learning medium, $H M I$ provides the effectiveness of information required so that designing can be efficiencyly carried out. In this research, a trainer for program examiner by the student kit was designed and fabricated. Following this the trainer kit was tested. The result showed that the use of CX Designer based HMI simulation can improve the understanding of the logic of a series of programs for PLC programming skills training.
\end{abstract}

Keywords: PLC, HMI, CX Disigner, CX-Programmer

\section{Pendahuluan}

Pendidikan adalah suatu perusahaan yang bekerja secara sistematis sesuai dengan tanggung jawab yang diberikan sehingga memungkinkan mahasiswa untuk memengaruhi dan menentukan karakteristik pendidikan yang diinginkan [1]. Harapan ini mengarah pada proses pematangan diri, yang membuat mahasiswa lebih mandiri dikemudian. Salah satu cara untuk mencapai tujuan tersebut adalah dengan mengembangkan proses pengajaran dalam bentuk proses inovatif model pembelajaran dengan meningkatkan efiktivitas proses pembelajaran.

Berdasarkan hasil observasi pembelajaran programmable logic controller yang selanjutnya disebut PLC, ditemukan bahwa interaksi dengan proses pembelajaran tampak pasif, mahasiswa hanya mendengarkan saja, yang menghambat proses pembelajaran. Banyak faktor yang menjadi penghambat dalam penelitian ini, diantaranya adalah kurangnya media pembelajaran praktikum PLC, jenis-jenis trainer PLC yang berbeda-beda, sehingga setiap mahasiswa perlu mengetahui trainer tersebut sebelum digunakan, dan alat praktis 
yang jumlahnya terbatas (seperti kabel jumper, sakelar dan lampu indikator. Faktor-faktor tersebut menyebabkan mahasiswa salah memahami pelajaran.

Perlu media pembelajaran layak untuk setiap mahasiswa berlatih agar keterampilan yang dibutuhkan dapat tercapai dengan baik. Media pembelajaran praktikum ini menjadi sangat penting agar mahasiswa sedang praktikum tidak ada kebingungan, kurang minat, dan motivasi belajar. Media pembelajaran merupakan salah satu poin penting untuk mencapai tujuan-tujuan pembelajaran, distribusi bahan ajar media interaktif bisa merangsang minat, perasaan, perhatian dan pemikiran [2]. Salah satu media yang bisa memecahkan masalah tersebut merancang dan membangun simulasi trainer HMI berdasarkan CX designer, yang dapat digunakan setiap mahasiswa selama pembelajaran PLC.

Programmable logic controller (PLC) adalah perangkat fungsional untuk mengelolah proses industri. PLC tipikal mencakup prosesor yang dilengkapi dengan sejumlah modul seperti input, output, memori, komunikasi, dan modul khusus. Sinyal yang diproses oleh modul input dan output dapat berupa tegangan (0-5 V atau 0-10 V) atau arus (4-20 mA). Cara paling umum untuk menulis program adalah dengan pemograman tangga (diagram ladder). Pemograman diagram tangga mirip dengan rangkaian relay pada rangkaian listrik, sehingga mudah untuk dipahami.

Human Machine Interface (HMI) adalah media antar muka yang membantu operator memberikan kemampuan untuk melakukan perubahan pada peralatan dilapangan. Data yang digunakan dalam tampilan $\mathrm{HMI}$ dapat berasal dari tautan objek dan server kontrol proses (OPC) tertanam dan pertukaran data dinamis (DDE) oleh karena itu, HMI dapat bertindak sebagai klien OPC atau Klien DDE. Di dalam pengoperasiannya, perangkat HMI terbagi menjadi dua kategori yaitu operator workstation dan engineering workstation [3]. Trainer HMI merupakan media pembelajaran simulasi, model simulasi bertujuan untuk memberikan pengalaman yang realistis dengan membuat contoh dan bentuk pengalaman yang mirip dengan lingkungan nyata tanpa adanya risiko bahaya [4].

\section{MetOde}

PLC yang digunakan dalam penelitian ini adalah PLC Omron CJ1m series yang dilengkapi dengan modul input dan output serta komunikasi Ethernet [5]. Pada penelitian ini perancangan dilakukan secara eksperimental, yaitu menghasilkan produk dengan modul pelatihan otomasi HMI berdasarkan CX Designer yang terintegrasi.

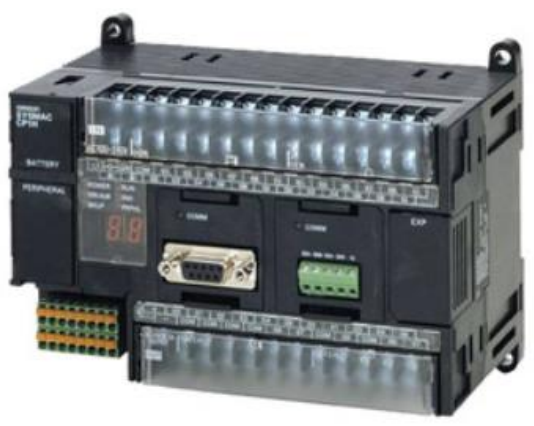

Gambar 2.1 PLC tipe Cj1m

Pembuatan HMI pada penelitian ini menggunakan software CX designer yang di produksi oleh Omron, yang berfungsi untuk menvisualisasikan proses kerja, peristiwa, ataupun proses yang terjadi secara nyata dengan membuat simulasi terlebih dahulu. HMI juga berguna bagi mahasiswa atau operator untuk mengidentifikasi kesalahan pada program sebelum program dijalankan pada sistem nyata di industri. Diagram berikut memperlihatkan alur kerja di CX designer. 


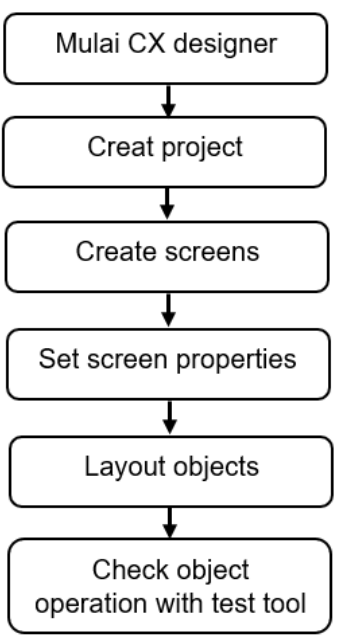

Gambar 2.2 Diagram garis besar alur operasi pada CX designer

Untuk memulai $C X$-Designer pergunakan langkah-langkah sebagai berikut: Klik start $>$ program $>$ OMRON $>$ CX-One $>C x$-Designer. Untuk menampilkan projek baru pilih $>$ New Project, pilih model HMI Omron yang akan digunakan pada bagian Model, semisal NS15. sedangkan system version pergunakan default 13.0. pada bagian project file, file name dan location penyimpanan file $C X$-Designer. Lalu pilih $O K$ untuk memulai project baru. Jendela atau new screen berfungsi untuk membuat deskripsi dari tampilan yang akan dibuat pada layar HMI. Seperti tampilan awal sistem, isi bagian No dengan 0, dan beri judul tampilan halaman 0 dengan Home, pada bagian Title. Setelah mengkonfigurasi nama dan halaman tampilan, jika ingin mengubah warna background tampilan ke warna yang diinginkan misalkan warna putih, bisa menggunakan klik kanan pada area tampilan, kemudian pilih menu screen > background. Pada screen property terdapat juga pilihan untuk mengubah ukuran screen.

Untuk membuat tampilan halaman HMl langkah yang harus dilakukan sebagai berikut: pada area screen, ditambahkan functional object seperti push button on dan off, word button, bit lamp, label. Seperti pertama-tama pilih push button kemudian drag di area screen. Lakukan konfigurasi alamat $\mathrm{ClO}$ dari input push button yaitu 0.00 dan bit lamp 10.00, dengan double klik pada masing-masing functional object. Selanjutnya pengaturan dari functional object yang digunakan sebagai contoh alternate bila menginginkan tombolnya sebagai latch. Kemudian atur write address dengan memilih menu set1, maka akan tampil jendela advance setting. Pengaturan alamat dari pushbutton ini sesuai dengan diagram ladder PLC semisal IO 0.00. Lakukan konfigurasi ini pada bit lamp, dimana alamat bit lamp yaitu 10.00 pada PLC Omron.

Menjalankan simulasi HMI yang dibuat menggunakan $C X$-Programmer dan $C X$ Designer dengan langkah-langkah sebagai berikut: pilih menu yang terdapat pada tools > test.

Lakukan konfigurasi pada jendela menu test dengan start testing offline bila menginginkan pengujian secara offline. Connect to $c x$-simulator apabila menginginkan simulasi yang dibuat dihubungkan dengan intergrated simulator pada $c x$ programmer, jadi pada simulasi bisa melakukan tampilan input maupun output pada $c x$ designer tanpa harus menghubungkan dengan PLC sesungguhnya. Pilihan menu test lainnya bisa memilih connect to PLC apabila menginginkan simulasi yang dibuat digunakan untuk mengontrol dan memonitoring secara langsung input atau output pada PLC sesungguhnya.

\section{Hasil dan Pembahasan}

Penelitian yang dilakukan ini menggunakan jenis PLC yaitu Omron Sysmac Cj1m yang memiliki 20 buah Input/Output (I/O). Berikut contoh nama-nama komponen dari PLC Cj1m (OMRON, 2009), di antaranya (1) Terminal L1 dan L2/N dihubungkan ke 220 Vac, (2) Terminal Com Input, (3) Terminal Input 00.01-00.11, (4) Terminal Output 10.01-10.07, (5) 
Serial Port, untuk Transfer program dari komputer ke PC, (6) Power Supply Internal 24 VDc, (7) Standart Feature USB peripheral port.
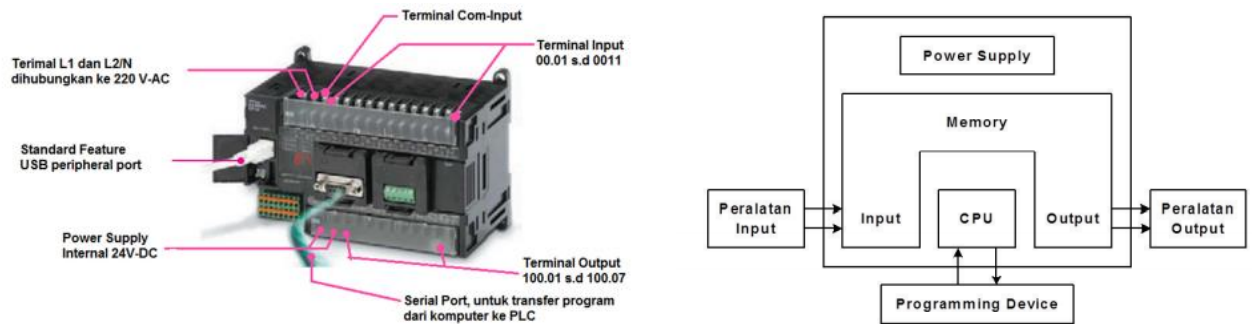

Gambar 3.1 Komposisi PLC

Dengan menggunakan metode pemrograman diagram tangga untuk menulis program, perangkat lunak yang digunakan untuk menjalankan PLC adalah CX-Programmer. Selain fungsi pemrograman, perangkat lunak juga dapat digunakan untuk mengatur dan mengoperasikan PLC, seperti program debugging, menampilkan alamat dan nilai, pengaturan dan pemantauan, dan program jarak jauh melalui jaringan.

Metode pemrograman ladder ini menyediakan cara untuk menulis kode program yang kemudian diubah menjadi kode mesin sehingga kode tersebut dapat diterjemahkan oleh mikroprosesor di PLC. Penulisan kode program sama dengan menulis rangkaian switching pada rangkaian listrik atau instalasi listrik. Diagram tangga pada PLC terdiri dari dua garis horizontal yang berguna untuk pengisian komponen I/O dan fungsinya berupa rangkaian-rangkaian antara dua garis vertikal yang merepresentasikan saluran tenaga listrik.

Program ladder dalam penelitian ini menggunakan software CX-Programmer yang terintegrasi penuh dengan semua jenis PLC Omron. Berikut ini adalah langkah-langkah untuk membuat program tangga di CXProgrammer untuk Cj1m PLC:

\subsection{Pembuatan program baru}

Program baru menggunakan CX-Programmer caranya dengan memilih file - New atau bisa menekan $\mathrm{Ctrl}+\mathrm{N}$ atau klik tombol New pada Toolbar ditunjukan pada gambar 3.2.

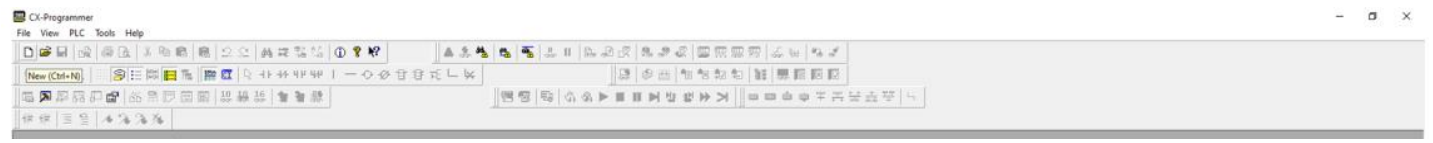

Gambar 3.2 Membuat program baru

\subsection{Menentukan tipe PLC}

Menentukan tipe PLC dilakukan untuk alamat dan ladder diagram yang dibuat agar sesuai dengan PLC yang digunakan, hal ini dilakukan supaya program yang sudah dirancang tidak terjadi error atau tidak bisa berjalan sesuai yang diinginkan. Cara menentukan tipe PLC dengan memilih Cj1m. Memilih CPU Type dengan mengklik setting. mengkonfirmasi USB sebagai Network Type pilih Toolbus ditunjukan pada gambar 3.3.

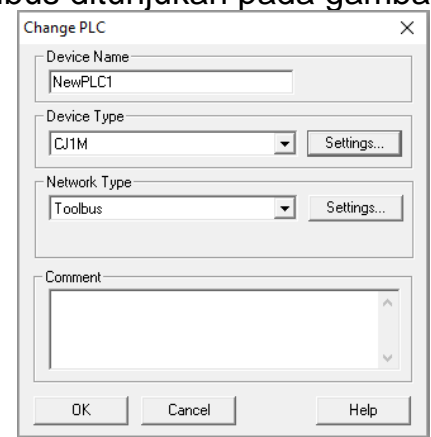

Gambar 3.3 Menentukan tipe perangkat PLC 


\subsection{Lembar kerja di CX-Programmer}

Sesudah melakukan pengaturan tipe PLC, akan muncul tampilan utama new project. Program ladder dapat dibuat, ditulis, diedit, serta disimulasikan pada lembar kerja. Jumlah kolom dalam lembar kerja dapat diatur, bertujuan untuk menyelesaikan I/O yang akan digunakan. Tampilan lembar kerja CX-Programmer ditunjukan pada gambar 3.4.

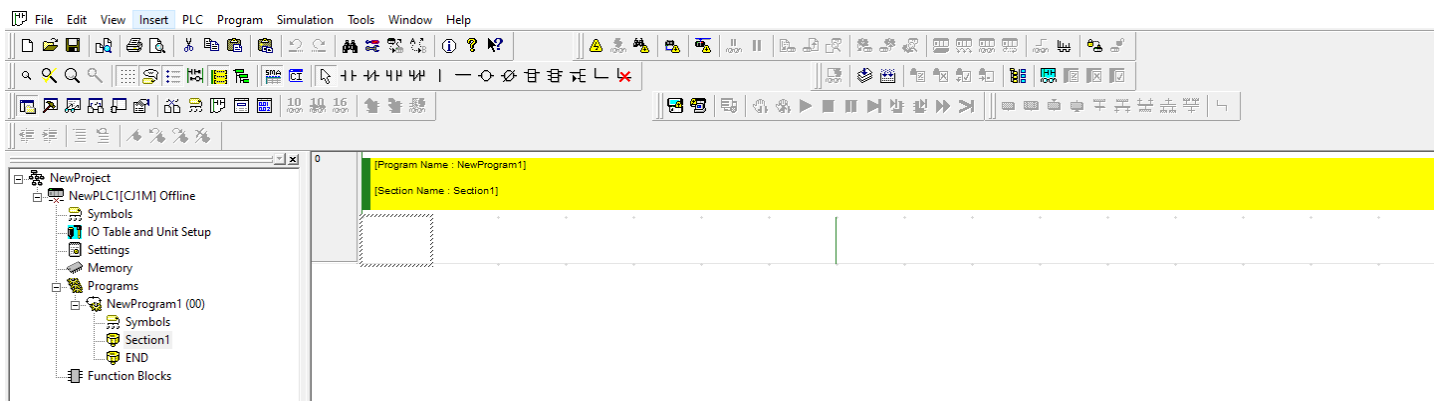

Gambar 3.4 Lembar Kerja Cx-Programmer

\subsection{Pemograman Ladder diagram}

Pada pengetesan simulasi trainer PLC Cj1m, peneliti membatasi jumlah input sebanyak dua buah yaitu satu kontak push button dengan tipe momentary untuk menghidupkan lampu indikator PB ON dengan alamat 0.05 , dan satu kontak push button dengan tipe momentary untuk mematikan lampu indikator PB OFF dengan alamat 0.06. Bagian output sebanyak satu buah yang berupa lampu indikator dengan alamat 10.00 yang akan menerima sinyal dari alamat 0.05 dan 0.06. Langkah-langkah memasukkan program tangga ke dalam lembar kerja dan tampilan kode program ditunjukkan pada Gambar 3.5

1. Pilih kontak normally open (NO) pada kolom dan baris pertama. Input 0.05 untuk PB ON

2. Pilih kontak normally close (NC) pada baris pertama dan kolom kedua. Input 0.06 utuk PB OFF

3. Pilih Output coil (out) pada baris pertama dan kolom terakhir. Output 10.00 untuk LAMPU

4. Pilih rangakaian OR pada baris kedua dan kolom pertama. Output 10.00 untuk LAMPU

5. Pilih intruksi END untuk mengakhiri kode program

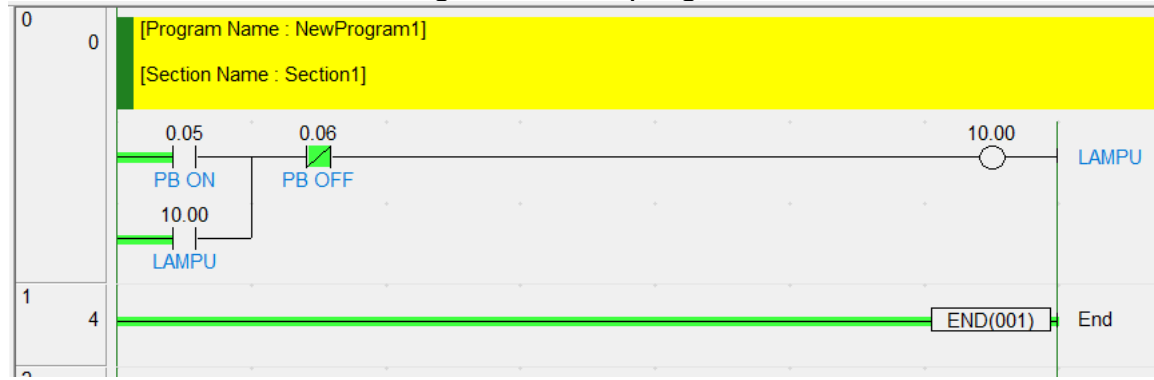

Gambar 3.5 Kode pemograman ladder diagram

\subsection{Instruksi Program}

Suatu program membutuhkan instruksi agar mahasiswa atau operator dapat mengert dalam menjalankan perintah-perintah fungsi I/O. instruksi secara lengkap dalam pengetesan perancangan simulasi terdapat pada tabel sebagai berikut :

Tabel 3.1 langkah pengujian perancangan simulasi

\begin{tabular}{|l|l|l|l|}
\hline Langkah & PB ON (0.05) & PB OFF (0.06) & Lampu (10.00) \\
\hline 1 & aktif & Tidak aktif & Hidup \\
\hline 2 & Tidak aktif & Tidak aktif & Hidup \\
\hline 3 & Tidak aktif & aktif & Mati \\
\hline 4 & Tidak aktif & Tidak aktif & Mati \\
\hline
\end{tabular}


1. Tombol PB ON 0.05 ditekan maka Lampu 10.00 akan aktif (hidup)

2. Tombol PB ON 0.05 dilepas maka Lampu 10.00 tetap aktif (hidup)

3. Tombol PB OFF 0.06 di tekan maka Lampu 10.00 akan padam (mati)

4. Tombol PB OFF 0.06 di lepas maka Lampu 10.00 tetap padam (mati)

Tampilan simulasi HMI menggunakan CX designer saat pertama kali di jalankan memperlihatkan suatu input dan output berupa sakelar dan lampu dengan jumlah alamat input 10 dan jumlah alamat output 10. alamat input mulai dari 0.00 sampai 0.09 dan alamat output mulai dari 10.00 sampai 10.09

SIMLASI OTOMASI PLC $20 \mathrm{I} / 0$

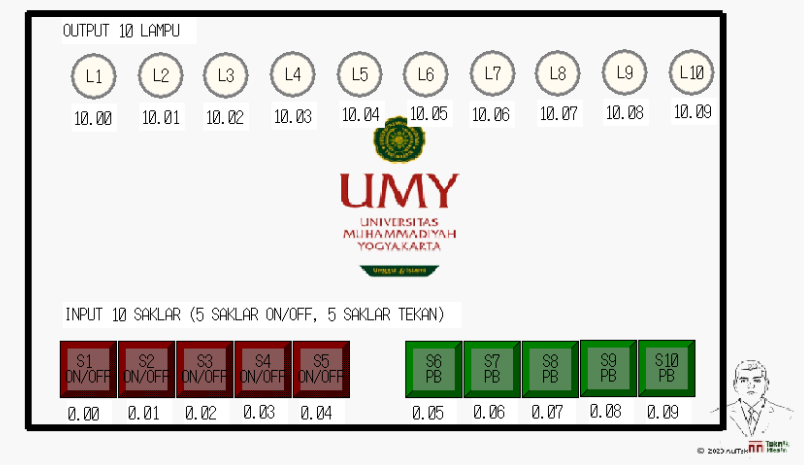

Gambar 3.6 Tampilan layar utama

Eksekusi uji kode program di CX-Designer dan CX-Programmer dengan menekan tombol perintah. Saat menguji kode program, peneliti melakukan atau mengujinya melalui CX-Programmer. Berikut ini adalah langkah-langkah proses untuk pengujian dengan menekan tombol "Simulasi Terpadu PLC-PT" dan "Mulai". Setelah menyelesaikan langkahlangkah ini, mulailah proses transfer data yang disimulasikan

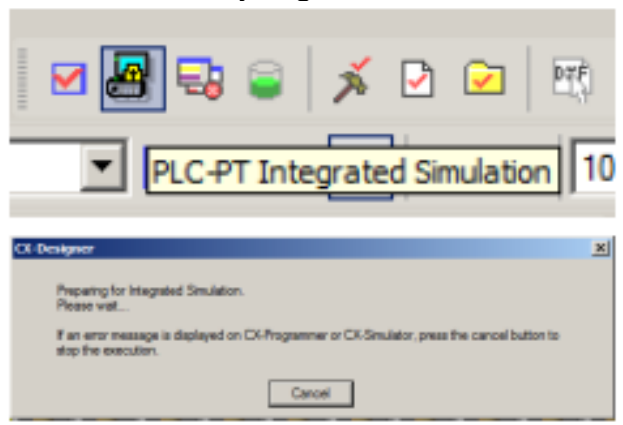

Gambar 3.7 Eksekusi simulasi program

Setelah proses sinkronisasi selesai, akan muncul menu "Test Mode", seperti pada Gambar 3.7. Tampilan pemrograman ladder pada CX-Programmer juga akan terintegrasi dengan Simulation, ini berarti apa yang terjadi pada mode uji tidak akan terlihat pada rangkaian pemrograman ladder. Gambar berikut menunjukkan simulasi trainer dalam "mode uji" dan pemrograman diagram tangga dalam perangkat lunak CX-Programmer, seperti yang ditunjukkan pada Gambar 3.8. 


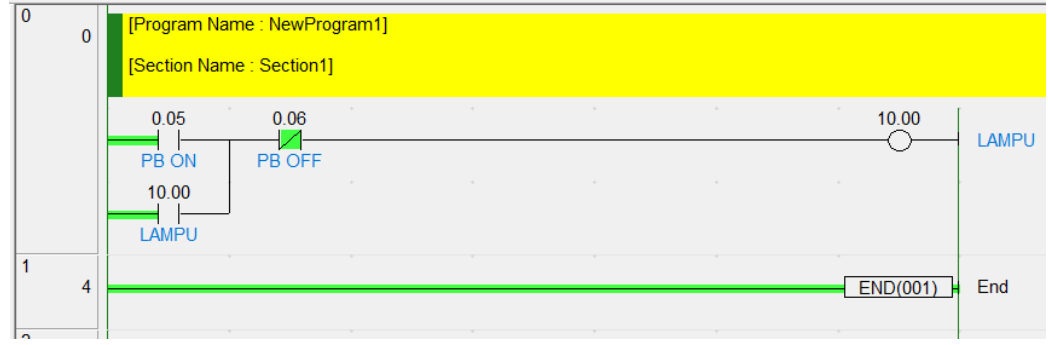

Gambar 3.8 Kondisi awal simulasi

Pengujian dalam simulasi trainer ini merupakan contoh dari prinsip fungsi rangkaian penguncian (selfholding). Rangkaian penguncian (selfholding) adalah rangkaian yang dapat mempertahankan status keluaran saat kondisi masukan berubah. Rangkaian jenis ini banyak digunakan pada aplikasi sakelar pada PLC karena memiliki mekanisme yang sederhana dan mudah digunakan. Langkah-langkah pengujian sebagai berikut:

Pengujian pertama, jika tomnol PB ON 0.05 di tekan maka lampu 10.00 akan hidup. Tombol PB ON adalah input normally open pada kotak input dengan alamat 0.05 menyala berwarna hijau apabila di tekan. Lampu indikator pada kotak output dengan alamat 10.00 berwarna merah menyala. Pada kode program cx programmer tampilan akan terlihat garis warna hijau dari input disisi kiri menuju ke output pada sisi kanan dengan kondisi terhubung, dapat ditunjukan pada gambar 3.9.

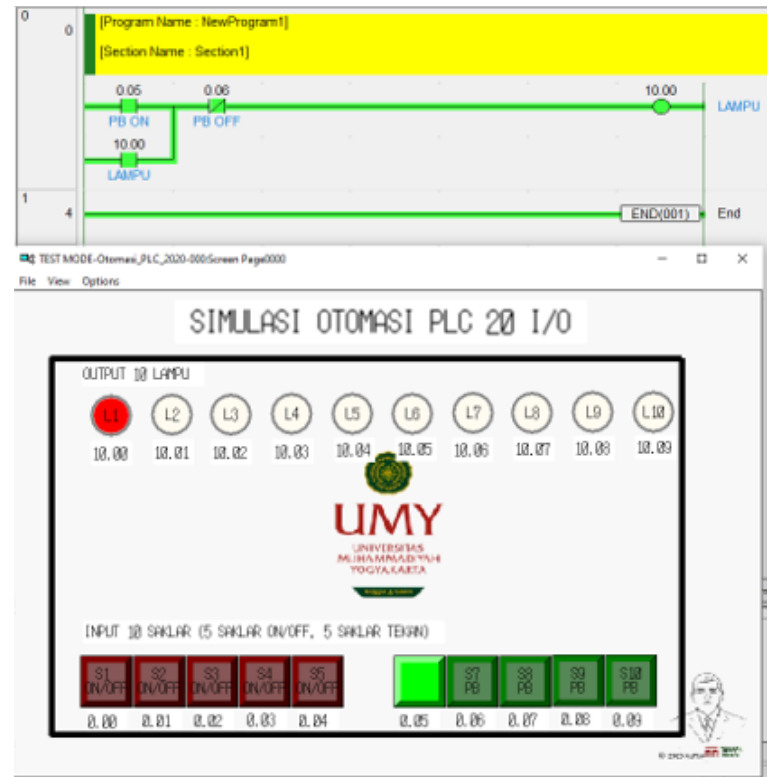

Gambar 3.9 Pengujian pertama tombol PB ON ditekan

Pengujian kedua, jika tomnol PB ON 0.05 di lepas maka lampu 10.00 akan tetap hidup. Tombol PB ON adalah input normally open pada kotak input dengan alamat 0.05 berwarna hijau tidak menyala apabila dilepas. Lampu indikator pada kotak output dengan alamat 10.00 berwarna merah tetap menyala. Pada kode program cx programmer tampilan akan terlihat garis warna hijau dari input disisi kiri menuju ke output pada sisi kanan dengan kondisi tetap terhubung, dapat ditunjukan pada gambar 3.10. 

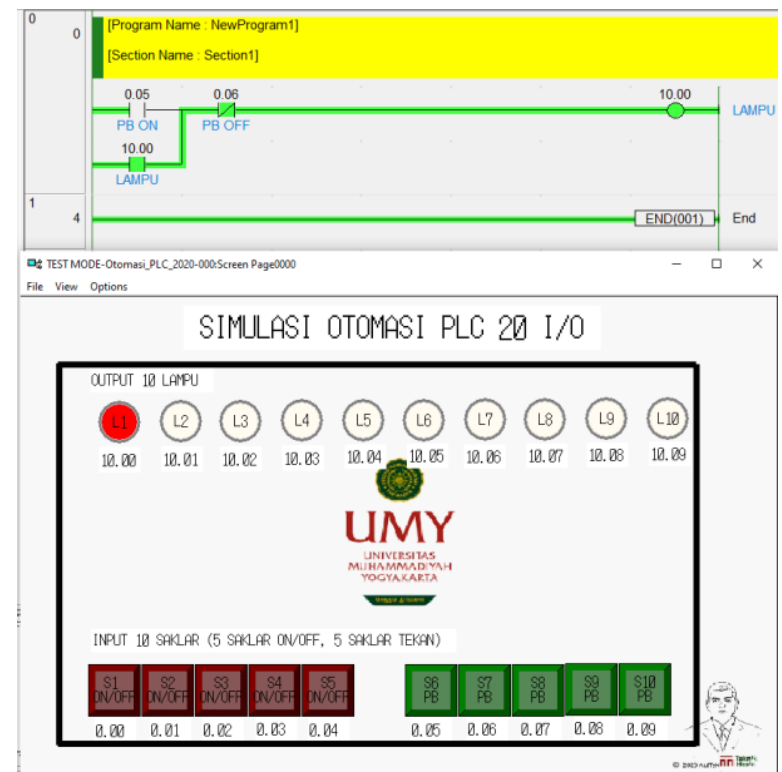

Gambar 3.10 Pengujian kedua tombol PB ON dilepas

Pengujian ketiga, jika tomnol PB OFF 0.06 ditekan maka lampu 10.00 akan padam (mati). Tombol PB OFF adalah input normally close pada kotak input dengan alamat 0.06 menyala berwarna hijau apabila ditekan. Lampu indikator pada kotak output dengan alamat 10.00 berwarna merah tidak menyala. Pada kode program cx programmer tampilan akan terlihat garis warna hijau dari input disisi kiri menuju ke output pada sisi kanan dengan kondisi terputus, dapat ditunjukan pada gambar 3.11.
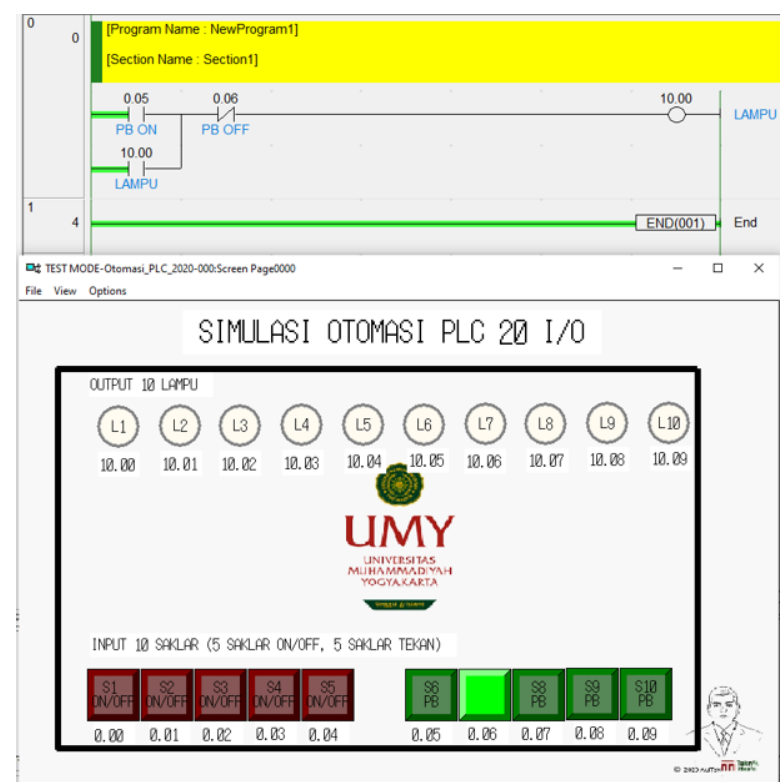

Gambar 3.11 Pengujian ketiga tombol PB OFF ditekan

Pengujian keempat, jika tomnol PB OFF 0.06 dilepas maka lampu 10.00 akan padam (mati). Tombol PB OFF adalah input normally close pada kotak input dengan alamat 0.06 tidak menyala berwarna hijau apabila dilepas. Lampu indikator pada kotak output dengan alamat 10.00 berwarna merah tidak menyala. Pada kode program cx programmer tampilan akan terlihat garis warna hijau dari input disisi kiri menuju ke output pada sisi kanan dengan kondisi tetap terputus, dapat ditunjukan pada gambar 3.12. 


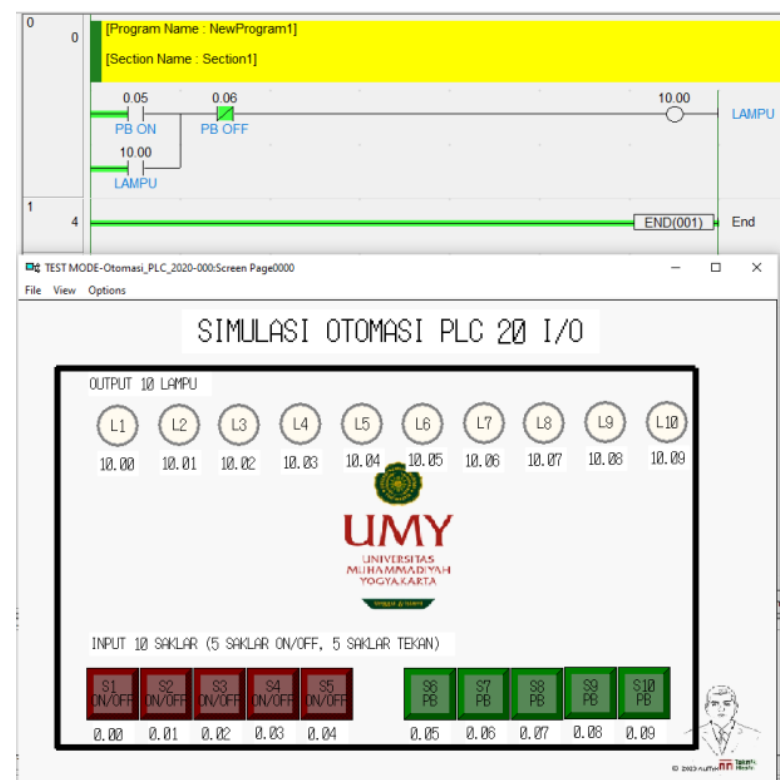

Gambar 3.12 Pengujian keempat tombol PB OFF dilepas

\section{KesimpUlan}

Peralatan trainer simulasi PLC telah berhasil didisain dan dibuat dan dapat berjalan dengan baik dan benar. Pemilihan saklar sebelum melakukan pengoperasian memberikan kemudahan dalam prakteknya tanpa harus mengganti komponen terlebih dahulu yang akan membuang waktu. Jumlah I/O dalam simulasi disediakan 10 input dan 10 output. Melalui cara yang sederhana dan fleksibel ini diharapkan mahasiswa atau operator yang mempelajari PLC akan termotivasi, tertarik dan terlatih untuk menyelesaikan masalah dibidang kendali PLC, karena mahasiswa atau operator dapat melihat sistem yang direncanakan dengan jelas dan intuitif.

\section{DAFTAR PUSTAKa}

[1] Munib, A. Pengantar IImu Pendidikan. Semarang: UPT MKK UNNES; 2004

[2] Daryanto. Media Pembelajaran. Yogyakarta: Gava Media; 2013

[3] Fiset, J. Y. Human-Machine Interface Design for Process Control Applications. USA: ISAInstrumentation, System, and Automation Society; 2009

[4] Rusman. (2012). Belajar dan Pembelajaran Berbasis Komputer. Bandung: Alfabeta; 2012

[5] OMRON. SYSMAC CJ1m CPU Unit: Introduction Manual. Tokyo, JAPAN: OMRON Corporation; 2009

[6] Bliesener, R, et. al. Programmable Logic Controllers, Festo Didactic GmbH, Denkendorf; 2002

[7] Mairodi. Implementasi Filter kalman pada Sistem Kontrol Menggunakan PLC Secara Realtime. Tesis. Program Instrumentasi dan Kontrol, Institut Teknologi Bandung; 2006

[8] Pressman, R. Software Engineering: a practitioner's approach. New York: McGrawHill; 2010

[9] Luo Wenhua, Designing and Implementation of Education Simulation System Base on PLC, Computer Crime Investigation Depatnnent, China Criminal Police University, Shenyang, China, 2010 
[10] Bankole I. Oladapo, V.A. Balogun, A.O.M. Adeoye, C.O. ljagbemi, Afolabi S. Oluwole, I.A. Daniyan, A. Esoso Aghor, Asanta P. Simeon, Model design and simulation of automatic sorting machine using proximity sensor, 2016

[11] Paulo Moura Oliveira, José Boaventura Cunha and Filomena Soares, Innovating in Control Engineering Teaching/Learning with Smartphones, 2019

[12] Peter Yakimov, Atanas lovev, Nikolay Tuliev and Emiliya Balkanska, Development of Hardware and Software Methods and Tools for a Successful PLC Training, 2019 